\title{
Medicaid managed care: how to target efforts to reduce costs
}

Mary E Charlson ${ }^{1,5^{*}}$, Martin T Wells ${ }^{2}$, Balavenkatesh Kanna ${ }^{3}$, Van Dunn ${ }^{4}$ and Walid Michelen ${ }^{3}$

\begin{abstract}
Background: To be successful, cost control efforts must target Medicaid Managed Care (MMC) beneficiaries likely to incur high costs. The critical question is how to identify potential high cost beneficiaries with simple, reproducible, transparent, auditable criteria. Our objective in this analysis was to evaluate whether the total burden of comorbidity, assessed by the Charlson comorbidity index, could identify MMC beneficiaries who incurred high health care costs.
\end{abstract}

Methods: The MetroPlus MMC claims database was use to analyze six months of claims data from 07/07-12/07; the analysis focused on the total amount paid. Age, gender, Charlson comorbidity score, serious mental illness and pregnancy were analyzed as predictors of total costs.

Results: We evaluated the cost profile of 4,614 beneficiaries enrolled at MetroPlus, an MMC plan. As hypothesized, the comorbidity index was a key correlate of total costs $(p<.01)$. Yearly costs were more related to the total burden of comorbidity than any specific comorbid disease. For adults, in addition to comorbidity $(p<.01)$ both serious mental illness $(p<.01)$ and pregnancy $(p<.01)$ were also related to total costs, while age, drug addiction and gender were not. The model with age, gender, comorbidity, serious mental illness, pregnancy and addiction explained $20 \%$ of the variance in total costs. In children, comorbidity $(p<.01)$, serious mental illness $(p<.01)$, addiction $(p<.03)$ and pregnancy $(p<.01)$ were associated with log cost; the model with those variables explained $6 \%$ of the variance in costs.

Conclusions: Comorbidity can be used to identify MMC beneficiaries most likely to have high costs.

Keywords: Comorbidity, Multiple chronic conditions, Medicaid, Prediction of cost, Predictive models, Cost containment, Managed care, Cost analysis, Prediction rules

\section{Background}

States have steadily increased mandates for Medicaid recipients to enroll in Medicaid Managed Care (MMC). As a result, $70 \%$ of the 60 million Medicaid beneficiaries are now in a MMC plan [1]. While some specific MMC programs have shown potential cost savings primarily by reducing inpatient use [2], an analysis of the 1991-2003 experience with MMC mandates in 50 states found that their impact on overall costs was negligible [3].

\footnotetext{
* Correspondence: mecharl@med.cornell.edu

${ }^{1}$ Division of Clinical Epidemiology and Evaluative Sciences Research and Center for Integrative Medicine at Weill Cornell Medical College, New York, USA

${ }^{5}$ Center for Integrative Medicine, Weill Cornell Medical College, 1300 York Avenue, Box 46, New York, NY 10065, USA

Full list of author information is available at the end of the article
}

It has been estimated that under the Patient Protection and Affordable Care Act 25\%, of U.S. residents are likely to be insured by Medicaid [4], increasing the need to identify potential high cost MMC beneficiaries with simple, reproducible, and auditable criteria that can be applied prospectively as patients enroll.

Previously among primary care patients, we found that average yearly total costs rose exponentially as the Charlson comorbidity rose above 4 [5]. However, the weakness of this prior study was that our cost data captured only costs of primary care patients at one health center (i.e., New York Presbyterian), and not outpatient or inpatient costs for external providers [5]. The Charlson comorbidity index can be assessed by questionnaire, analysis of medical records or claims data $[6,7]$. 
In this analysis of beneficiaries enrolled in an MMC plan, our objective was to evaluate whether the comorbidity index identified Medicaid beneficiaries who incurred high health care costs, controlling for other important contributors to costs in Medicaid patients, such as mental illness and pregnancy [8]. Based on our previous work, we hypothesized that as the comorbidity index rose above 4 , there would be an exponential rise in mean yearly cost. If so, the comorbidity index, which can be assessed during a short interview, could be used to identify patients likely to incur high costs at the time of enrollment including those who will be newly enrolled under the Affordable Care Act.

\section{The population}

Lincoln Medical and Mental Health Center (Lincoln), serves the 654,360 predominately Latino (69\%) and African American (29\%) residents of the South Bronx, who have a median household income of $\$ 16,000$. Lincoln Medical and Mental Health Center, is part of New York City's Health and Hospitals Corporation (HHC) - a part owner of Metro Plus which is an MMC plan that assumes risk on all patients assigned to its primary care physicians. The study population includes all enrollees in the MMC plan who have primary care in the Lincoln system, including those enrolled through Medicaid, Child Health Plus, Family Health Plus, and Medicaid HIV. It does not include Medicare/Medicaid patients.

The project was reviewed and approved by the IRB at Lincoln Medical and Mental Health Center, at Weill Cornell Medical College and the HHC central research office. All data was de-identified. For research purposes, the data provided by Metroplus was restricted only to patients who had an assigned primary care physician at Lincoln.

\section{Sample}

The MetroPlus claims database was used to identify those patients for whom Lincoln was assigned as the primary care provider. The analysis focused on patients who had an assigned primary care provider at Lincoln between 07/07-12/07. There were 4,614 MetroPlus members who met the criteria: 2,218 adults and 2,396 children.

\section{Study variables}

The age, gender, primary language, line of service (Medicaid, Child Health Plus, Family Health Plus, Medicaid HIV), and zip code of residence were documented. Chronic diseases were ascertained from the ICD-9 codes assigned by MetroPlus MMC when patients received any service.

The Charlson comorbidity score was used to assess the aggregate burden of chronic disease [9]. The index assigns weights for specific diseases and the total score is calculated by adding the weights [6]. The 23 chronic diseases (including one medication) that comprise the Charlson Comorbidity Index and their assigned weights are as follows:

Weight of one: cerebrovascular disease, congestive heart failure, connective tissue disease, chronic obstructive pulmonary disease, dementia, depression, diabetes, hypertension, mild liver disease, myocardial infarction, peripheral vascular, ulcer disease or the use of warfarin;

Weight of two: hemiplegia, moderate/severe renal disease, diabetes with end organ damage, any tumor, leukemia, lymphoma or skin ulcers/cellulitis;

Weight of three: moderate to severe liver disease; Weight of 6: metastatic solid tumor or AIDS.

Aggregate ICD-9 codes were used to ascertain the Charlson index using the Deyo coding strategy [7]. In addition to chronic conditions that are included in the comorbidity index, substance abuse, mental illness and pregnancy were also recorded. Patients with ICD-9 codes of 303 or 305 were coded as addiction (drug or alcohol) and those with ICD-9 codes of 290, 300 or 307-317 as serious mental illness. Patients with ICD-9 codes of 640-677 were classified as pregnant.

\section{Costs}

Six months of claims data from $07 / 07-12 / 07$ from MetroPlus MMC costs were evaluated. Costs were assessed by setting and type. The MMC covered inpatient, outpatient, ER, laboratory tests, and prescription drugs; it did not cover dental services. Total costs were defined as the total claims paid; claims that were not paid did not contribute to total costs.

\section{Statistical analysis}

Adjusted costs for patients with specific chronic diseases were analyzed in order to document the cost of that disease alone, controlling for comorbidity. The adjusted comorbidity index was found by subtracting the weight for each disease from the comorbidity index; an index of zero means the patient had just one chronic disease. For example, when evaluating costs associated with diabetes, a patient with only diabetes ( and a comorbidity score of 1) would have an adjusted comorbidity score of 0 ; however, a patient with diabetes and hypertension would have an adjusted comorbidity score of 1 .

A two part regression modelling framework was used for modeling log total health care cost. Log total costs are used in the regression modeling in order to correct skewness. The first part of the two-part model is a binary outcome model that describes the distinction between non-users (zero cost) and users of services (non-zero 
cost), while the second part is a linear regression that describes the distribution of log total health care cost for patients who used services. Separate (two part) regression models were developed for adults and children $($ age $<18$ ). These regressions were all controlled for age and gender. Addiction (drug or alcohol) and pregnancy were also assessed in both the adult and child models [10].

Quantile regression was employed to assess the relationship between predictors and the upper 5\% and 10\% of the cost distribution, controlling for age, gender and mental health diagnoses [11]. Quantile regression focuses on the upper tail of the cost distribution so that patients with zero costs in the lower tail of the distribution do not heavily affect the estimates. The pseudo $R^{2}$ is the measure of model fit.

\section{Results}

Overall, as shown in Table 1, 48.1\% of the MMC beneficiaries were adults, $72 \%$ women, with an average age of $45.7 \pm 12.6$ years (a range of 18 to 73 years), while $51.9 \%$ were children with an average age of $7.6 \pm 4.9$ years (a range of .01 to 17.9 years). Of the adults, $1.8 \%$ were over 65 years of age. Of the children, $4.4 \%$ were less than one year of age. Overall, $86.9 \%$ of all children were enrolled through standard Medicaid, 2.2\% through Child Health Plus, a NY State insurance for children under the age of 19 who are not eligible for Medicaid; 8.9\% through Family Health Plus, a NY State plan for families not eligible for Medicaid; 0.7\% through a commercial MetroPlus

Table 1 Demographic and clinical characteristics of beneficiaries

\begin{tabular}{|c|c|c|}
\hline & Adults $(n=2,218)$ & Children $(n=2,396)$ \\
\hline Age ( sd) & $45.7 \pm 12.6$ & $7.6 \pm 4.9$ \\
\hline Female & $71.1 \%$ & $49.2 \%$ \\
\hline Medicaid & $78.2 \%$ & $95.0 \%$ \\
\hline Child health plus & $0 \%$ & $4.3 \%$ \\
\hline Family health plus & $18.5 \%$ & $0 \%$ \\
\hline Pregnancy & $4.2 \%$ & $0.2 \%$ \\
\hline Addiction & $4.2 \%$ & $0.3 \%$ \\
\hline Mental health & $7.4 \%$ & $1.1 \%$ \\
\hline Hypertension & $37.2 \%$ & $0.4 \%$ \\
\hline Diabetes ${ }^{\epsilon}$ & $21.4 \%$ & $0.5 \%$ \\
\hline Cancer $^{\infty}$ & $4.1 \%$ & $0.3 \%$ \\
\hline Asthma or COPD & $15.2 \%$ & $11.4 \%$ \\
\hline Depression & $7.1 \%$ & $0.3 \%$ \\
\hline Liver disease $^{\mathfrak{f}}$ & $3.7 \%$ & $0.1 \%$ \\
\hline HIV/AIDS & $2.6 \%$ & $0.4 \%$ \\
\hline
\end{tabular}

${ }^{\infty} 0.2 \%$ had metastatic disease.

$\epsilon_{2.3 \%}$ had end organ damage.

${ }^{\mathrm{E}} 2.9 \%$ with moderate-severe disease. plan; and $1.3 \%$, through a Medicaid HIV special needs plan. There were only 8 patients who were enrolled in Medicaid at the time of hospitalization. English was the primary language for $62 \%$ and Spanish for $36 \%$ of the patients.

Table 2 shows the distribution of beneficiaries and costs according to the comorbidity index. Overall, the $8.3 \%$ of adults with a comorbidity index $\geq 4$ incurred $30.1 \%$ of the costs. Among the children, a vast majority had a comorbidity score of 0 . Among children, the $12.7 \%$ with one or more chronic illnesses incurred $41.6 \%$ of the costs. The most common chronic diseases in children were asthma (11.3\%) and diabetes $(0.4 \%)$. The children with asthma had mean costs of $\$ 1,291 \pm \$ 7,683$, while those with diabetes had mean costs of $\$ 2,031 \pm \$ 2,013$, respectively. Costs did not differ according to enrollment plan, except for Medicaid HIV, where the costs were significantly higher $(\mathrm{p}<.04)$.

Overall, as comorbidity increased, total costs increased $(\mathrm{p}<.01)$. Costs for each chronic condition did not differ at lower levels of comorbidity. Costs according to specific chronic illnesses were also evaluated. Figure 1 shows the costs for chronic diseases impacting at least 100 beneficiaries according to the adjusted level of comorbidity. It demonstrates that costs are more a function of the total burden of comorbidity than of any specific comorbid disease. Figure 2 shows the distribution of patients according to the adjusted comorbidity index; the vast majority of beneficiaries, regardless of specific chronic illness, had a comorbidity index of zero or one.

The comorbidity index and total visits were correlated for adults $(\mathrm{R}=.29)$ and children $(\mathrm{R}=.21)$; however; the comorbidity index did not increase until the number of visits exceeded 20.

\section{Pregnancy}

The 94 women who were pregnant, including 4 adolescents, had a significantly increased cost of $\$ 4,104 \pm \$ 3,865$ $(\mathrm{p}<.01)$. Of the pregnant women, 75 with a comorbidity score of 0 had an average cost of $\$ 3,621$, while the 16 women with a comorbidity score of 1 had costs of $\$ 5,470$. Only 3 pregnant women had scores of 3 or more; they had average costs of $\$ 8,902$.

\section{Mental illness}

Costs for the 190 patients with severe mental illness, including major depression, bipolar illness, and schizophrenia, were also significantly higher $(\mathrm{p}<.003)$. Of these patients with serious mental illnesses, $86 \%$ were adults, and $14 \%$ children; both groups had similar costs. Of the 100 patients who had an addiction, 93\% were adults, and $7 \%$ children. Overall $3 \%$ of those with a comorbidity score of $0-1$ had mental illness, vs. $15 \%$ of those with a score $\geq 2$ $(\mathrm{p}<.01)$. Controlling for age, gender, comorbidity and 
Table 2 Beneficiaries and health care costs according to the Charlson comorbidity index

\begin{tabular}{|c|c|c|c|c|c|c|}
\hline Comorbidity & $\begin{array}{c}\text { Number of } \\
\text { beneficiaries }\end{array}$ & $\begin{array}{c}\text { Percent of } \\
\text { beneficiaries }\end{array}$ & $\begin{array}{l}\text { Total } \\
\text { costs }\end{array}$ & $\begin{array}{l}\text { Percent } \\
\text { of costs }\end{array}$ & $\begin{array}{c}\text { Unadjusted } \\
\text { cost per person }\end{array}$ & $\begin{array}{c}\text { Adjusted cost } \\
\text { per person }\end{array}$ \\
\hline \multicolumn{7}{|l|}{ Adults } \\
\hline $0 ¥$ & 1,203 & $54.2 \%$ & $\$ 886,611$ & $30.9 \%$ & $\$ 737$ & $\$ 774$ \\
\hline 1 & 605 & $27.3 \%$ & $\$ 459,195$ & $16.0 \%$ & $\$ 760$ & $\$ 741$ \\
\hline $2-3$ & 137 & $6.2 \%$ & $\$ 299,208$ & $10.4 \%$ & $\$ 2,184$ & $\$ 2,100$ \\
\hline$\geq 4$ & 183 & $8.3 \%$ & $\$ 843,996$ & $29.4 \%$ & $\$ 4,672$ & $\$ 4,553$ \\
\hline All & 2,128 & & $\$ 2,489,010$ & & & \\
\hline \multicolumn{7}{|l|}{ Children } \\
\hline 0 & 2,089 & $87.2 \%$ & $\$ 607,899$ & $62.1 \%$ & $\$ 291$ & $\$ 295$ \\
\hline 1 & 286 & $11.9 \%$ & $\$ 336,622$ & $34.4 \%$ & $\$ 1,177$ & $\$ 1,152$ \\
\hline $2-3$ & 5 & $0.2 \%$ & $\$ 6,250$ & $0.6 \%$ & $\$ 1,251$ & $\$ 1,442$ \\
\hline$\geq 4$ & 12 & $0.5 \%$ & $\$ 12,228$ & $1.3 \%$ & $\$ 1,020$ & $\$ 111$ \\
\hline All & 2,392 & & $\$ 962,999$ & & & \\
\hline
\end{tabular}

$¥$ excludes 94 pregnant women 75 pregnant women with a comorbidity score of 1 had an average cost of $\$ 3,621$, while the 16 women with a comorbidity score of 1 had costs of $\$ 5,470$.

Adjusted costs are adjusted for age, gender, mental health, and addiction.

pregnancy, patients with mental illness had almost double the costs than those without ( $\$ 1,345$ vs. $\$ 801)$.

\section{Hospitalization as a driver of costs}

As shown in Table 3, the rate of hospitalization and repeated hospitalization increased with increasing comorbidity ( $\mathrm{p}<.01$ for both). Two-thirds of the patients hospitalized were adults, while one-third were children $(\mathrm{p}<.01)$. Patients who were hospitalized incurred mean costs of $\$ 8,996$, while those not hospitalized had mean costs of $\$ 263$ ( $\mathrm{p}<.0001)$. Table 4 shows the average costs for patients according to comorbidity and total hospitalizations. Once comorbidity was taken into account, the hospitalization costs did not differ between children and adults $(\mathrm{p}<.7)$.

\section{Regression models}

Results for the regression analysis for the two part model of log total costs are given in Table 5. For a pooled model of adults and children of log total costs, the comorbidity index was a key correlate of total costs $(\mathrm{p}<.01$, 95\% CI $[.11, .14])$. Adults: In addition to comorbidity ( $\mathrm{p}<.01,95 \%$ CI $[.10, .14]$ ), serious mental illness ( $\mathrm{p}<.01$, $95 \%$ CI $[.06, .27])$, and pregnancy ( $\mathrm{p}<.01,95 \%$ CI $[.81$, 1.07]) were also correlated with costs, while age, drug addiction and gender were not. The model with age, gender, comorbidity, mental illness, pregnancy, and drug/alcohol addiction explained $20 \%$ of the variance in total costs $\left(\mathrm{R}^{2}=.20\right)$ Children: In children, comorbidity $(\mathrm{p}<.01,95 \%$ CI $[.10, .19])$, serious mental illness $(\mathrm{p}<.01,95 \%$ CI [.11, $.53]$ ), drug/alcohol addiction ( $\mathrm{p}<.03,95 \% \mathrm{CI}[.03, .81]$ ),

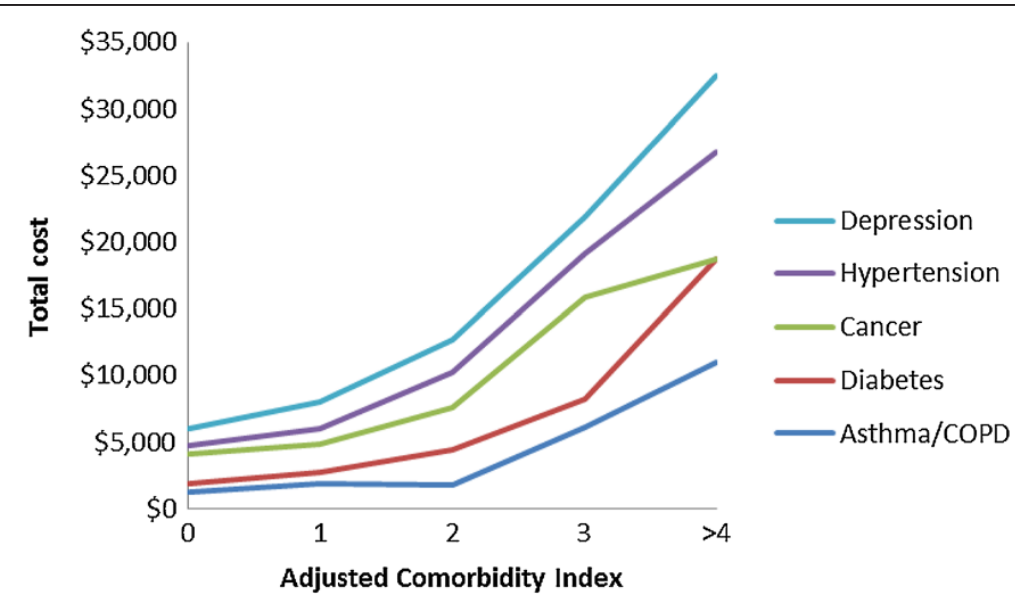

Figure 1 Costs according to specific chronic diseases and adjusted comorbidity score. The adjusted comorbidity index was found by subtracting the weight for each disease from the comorbidity index; an index of zero means the patient had just the one chronic disease. 


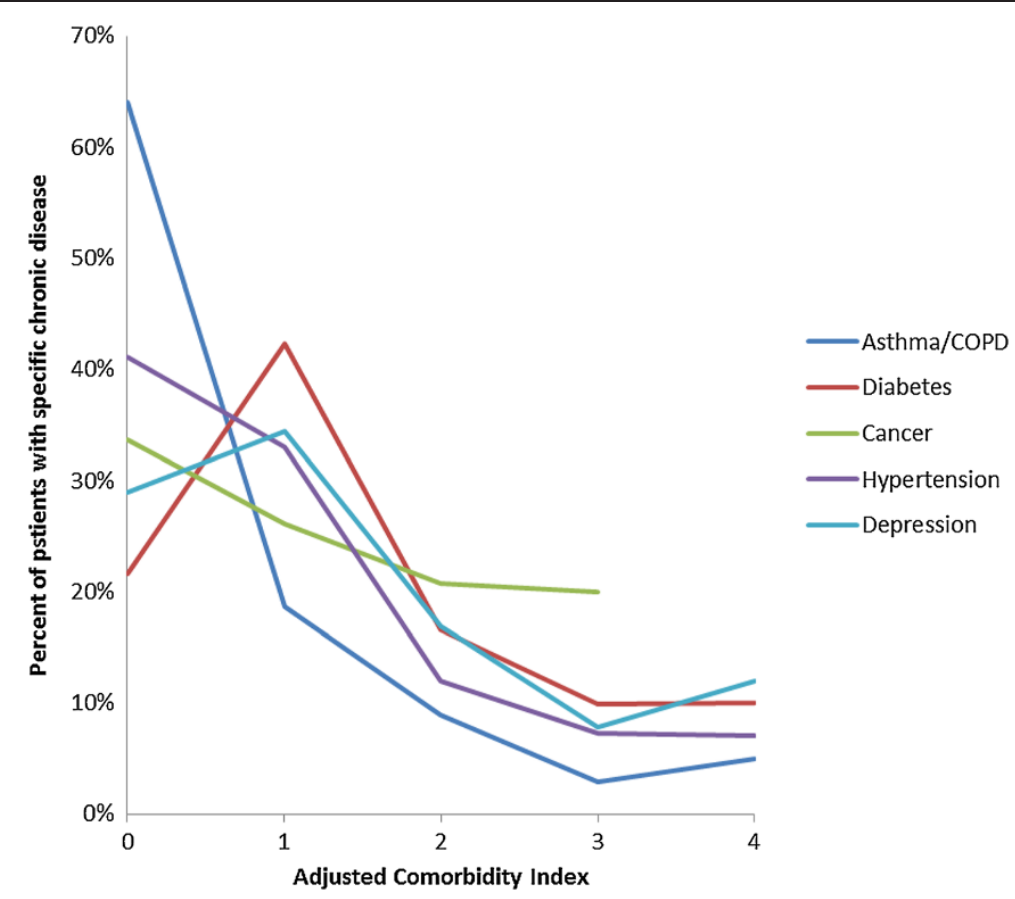

Figure 2 The distribution of patients with specific chronic diseases according to their adjusted comorbidity score.

and pregnancy $(\mathrm{p}<.01,95 \%$ CI $[.89,2.06])$ were associated with log cost, however, age and gender were not significantly related to log total costs; the explained variance was $6 \%\left(\mathrm{R}^{2}=.06\right)$.

Quantile regression was used to evaluate predictors of the top $5 \%$ and $10 \%$ of cost; the results are presented in Table 6 . The comorbidity index was significantly correlated with the top $5 \%$ and top $10 \%$ of costs for the pooled sample, as well as for adults and children separately. For the top 10\%, pregnancy and serious mental illness were significantly associated with log total costs in the adult sample while age was negatively correlated with log total costs in the child sample.

\section{Discussion}

This study showed that costs for MMC beneficiaries were primarily driven by the aggregate burden of comorbid disease, not by individual chronic illnesses. This echoes the findings of other studies about multiple chronic diseases as drivers of cost [12-14]. Although comorbidity has been defined in some studies as a measure of

Table 3 Percent of beneficiaries hospitalized according to comorbidity index

\begin{tabular}{lccc}
\hline Comorbidity & $\begin{array}{c}\text { One } \\
\text { hospitalization }\end{array}$ & $\begin{array}{c}\text { Two or more } \\
\text { hospitalizations }\end{array}$ & $\begin{array}{c}\text { Any } \\
\text { hospitalization }\end{array}$ \\
\hline $0-1$ & $3.7 \%$ & $1.0 \%$ & $4.7 \%$ \\
$2-3$ & $13.3 \%$ & $3.5 \%$ & $16.8 \%$ \\
$\geq 4$ & $10.2 \%$ & $6.6 \%$ & $16.8 \%$ \\
\hline
\end{tabular}

'other diseases' that can confound the outcomes of patients with a specific chronic illness, comorbidity is intrinsically a measure of the aggregate burden of disease.

For MMC programs, a critical question is how to control costs. To reduce costs, efforts have to focus on MMC beneficiaries most likely to incur high costs [15]. Some MMC efforts to decrease costs have targeted individuals who were high cost or high utilizers in the prior year [16-18] and others have focused on patients with specific chronic diseases [19-22]. However, most of these programs have not reduced costs [1,22-24].

MMC cost reduction efforts have also focused on beneficiaries who are predicted to have high costs using claims based models [22-28]. Most efforts to reduce costs have not taken comorbidity into account [20,22,28]. However, in this analysis, the $8 \%$ of patients with a comorbidity burden of four or more had $30 \%$ of costs. This data shows that strategies focused on a single chronic disease per se cannot efficiently target patients with a high burden of comorbidity who have high costs.

Table 4 Average cost according to number of hospitalizations and comorbidity index for all beneficiaries

\begin{tabular}{lccc}
\hline Comorbidity & $\begin{array}{c}\text { No } \\
\text { hospitalizations }\end{array}$ & $\begin{array}{c}\text { One } \\
\text { hospitalization }\end{array}$ & $\begin{array}{c}\text { Two or more } \\
\text { hospitalizations }\end{array}$ \\
\hline $0-1$ & $\$ 214$ & $\$ 5,511$ & $\$ 13,860$ \\
$2-3$ & $\$ 926$ & $\$ 4,651$ & $\$ 24,713$ \\
$\geq 4$ & $\$ 1,441$ & $\$ 14,468$ & $\$ 27,057$ \\
\hline
\end{tabular}


Table 5 Regression analysis for the two part model of log costs: Regression coefficients and t statistics

\begin{tabular}{|c|c|c|c|c|c|c|}
\hline & $\begin{array}{l}\text { Adults and } \\
\text { children } \\
\text { combined }\end{array}$ & $p$ & Adults & $p$ & Child & $p$ \\
\hline \multirow[t]{2}{*}{ Comorbidity } & 0.13 & $<.01$ & 0.13 & $<.01$ & 0.15 & $<.01$ \\
\hline & (16.66) & & $(14.89)$ & & (6.68) & \\
\hline \multirow[t]{2}{*}{ Age } & 0.00286 & $<.01$ & 0.00059 & & -0.00466 & \\
\hline & $(5.62)$ & & $(0.52)$ & & $(1.76)$ & \\
\hline \multirow[t]{2}{*}{ Female } & 0.00 & & 0.04 & & -0.05 & \\
\hline & $(0.00)$ & & $(1.22)$ & & $(1.91)$ & \\
\hline \multirow[t]{2}{*}{ Mental illness } & 0.19 & & 0.16 & & 0.32 & \\
\hline & $(4.19)$ & $<.01$ & $(3.09)$ & $<.01$ & $(2.98)$ & $<.01$ \\
\hline \multirow[t]{2}{*}{ Addiction } & 0.15 & & 0.13 & & 0.42 & \\
\hline & (2.46) & $<.05$ & $(1.91)$ & & $(2.13)$ & $<.05$ \\
\hline \multirow[t]{2}{*}{ Pregnancy } & 1.02 & & 0.95 & & 1.48 & \\
\hline & $(17.28)$ & $<.01$ & $(14.49)$ & $<.01$ & $(4.93)$ & $<.01$ \\
\hline \multirow[t]{2}{*}{ Intercept } & 2.23 & & 2.33 & & 2.29 & \\
\hline & (120.44) & $<.01$ & $(40.47)$ & $<.01$ & (83.58) & $<.01$ \\
\hline$R^{2}$ & 0.21 & & 0.20 & & 0.06 & \\
\hline$N$ & 3,427 & & 1,881 & & 1,546 & \\
\hline
\end{tabular}

Observed $\log 10$ Total Cost regression coefficients from a two part regression model (equations (1) and (2) in the Appendix). The coefficients for the zero inflation part of the two part model are not displayed. T-statistics are in parentheses.
Previous studies of Medicaid patients have had additional methodologic challenges [18]. Patients with such gaps in enrollment (churning in and out of Medicaid) have been shown to have highly variable costs [25].

\section{Limitations}

The major limitation is that our analysis focused on claims and cost data for 6 months only. We could not ascertain whether costs differed by season, since we had only 6 months of data. It would have been preferable to have a full year of data. We did not evaluate patients who were cycling in and out of enrollment, who are known to have greater cost variability [25]. In addition, our analysis focused on non-disabled beneficiaries [29]. Another limitation is that the comorbidity index has not been validated for children or pregnant women. While costs are clearly higher among pregnant woman when compared to those with equivalent comorbidity burdens, the results for pregnant women have to be interpreted with caution because the subgroup is small.

Another limitation is that this study involves one MMC plan, based at one hospital in NYC. A recent comprehensive synthesis has pointed out that Medicaid is not a single program but a diverse group of state run programs, and that as a result it is hard to generalize about the impact of MMC on costs [1]. Thus, by this analysis alone, we cannot be certain that these findings would be applicable to other states or plans [1]. However, in analyses of two other

Table 6 Quantile regression analysis of correlates of the top $10 \%$ and top $5 \%$ of costs: Regression coefficients and t statistics

\begin{tabular}{|c|c|c|c|c|c|c|c|c|}
\hline & \multirow{2}{*}{$\begin{array}{l}\text { Top } 10 \% \text { combined } \\
\text { Adult and child }\end{array}$} & \multicolumn{3}{|c|}{ Top 5\% combined } & \multirow[t]{2}{*}{ Top $10 \%$ of adults } & \multicolumn{3}{|c|}{ Top $10 \%$ child } \\
\hline & & $p$ & Adult and child & $p$ & & $p$ & & $p$ \\
\hline \multirow[t]{2}{*}{ Comorbidity } & 0.19 & & 0.21 & & 0.18 & & 0.33 & \\
\hline & $(10.83)$ & $<.01$ & $(7.01)$ & $<.01$ & $(10.67)$ & $<.01$ & $(3.70)$ & $<.01$ \\
\hline \multirow[t]{2}{*}{ Age } & 0.004 & & 0.00089 & & 0.00111 & & -0.02751 & \\
\hline & (3.33) & $<.01$ & $(0.45)$ & & $(0.49)$ & & $(2.58)$ & $<.01$ \\
\hline \multirow[t]{2}{*}{ Female } & -0.02 & & -0.05 & & -0.05 & & -0.12 & \\
\hline & $(0.43)$ & & $(0.66)$ & & $(0.91)$ & & (1.09) & \\
\hline \multirow[t]{2}{*}{ Mental illness } & 0.21 & & 0.10 & & 0.21 & & 0.42 & \\
\hline & $(1.86)$ & & $(0.53)$ & & (1.98) & $<.05$ & $(0.96)$ & \\
\hline \multirow[t]{2}{*}{ Addiction } & 0.20 & & 0.11 & & 0.23 & & 0.48 & \\
\hline & $(1.37)$ & & $(0.45)$ & & $(1.71)$ & & $(0.60)$ & \\
\hline \multirow[t]{2}{*}{ Pregnant } & 0.93 & & 0.77 & & 0.87 & & 0.98 & \\
\hline & $(6.68)$ & $<.01$ & (3.33) & $<.01$ & $(6.69)$ & $<.01$ & $(0.82)$ & \\
\hline \multirow[t]{2}{*}{ Intercept } & 2.83 & & 3.24 & & 3.03 & & 3.43 & \\
\hline & $(64.43)$ & $<.01$ & $(44.43)$ & $<.01$ & $(26.50)$ & $<.01$ & $(31.06)$ & $<.01$ \\
\hline Pseudo $R^{2}$ & 0.15 & & 0.12 & & 0.16 & & 0.07 & \\
\hline$N$ & 3,427 & & 3,427 & & 1,881 & & 1,546 & \\
\hline
\end{tabular}


populations, we have found a similar distribution of comorbidity and costs $[5,30]$.

\section{Conclusion}

Patients with higher comorbidity incur higher costs, suggesting that high comorbidity patients may be a key target for cost savings in MMC. The comorbidity score provides a reproducible, valid method of identifying patients with multiple chronic diseases, who should be targets for cost-saving efforts.

\section{Appendix}

\section{Statisical methods}

In a two-part model, explanatory variables often play different roles in the two parts of the model. Since the nonzero expenditure data are always positive and heavily skewed to the right, they are modeled with a lognormal distribution. Let $Z_{i}$ denote the observed total cost for the $i$ th subject and $X_{i}$ represent a vector of subject specific characteristics. With inflated zero values, the observed costs are assumed to represent realizations of random variables that have probability distributions describable by a mixture of a point mass at zero and a continuous distribution. That is, $Z_{i}=I\left[Y_{1 i}>0\right] \times 10^{Y 2 i}$, where $Y_{1 i}$ and $Y_{2 i}$ represent two latent random variables, $I[A]$ denotes the indicator of the event $A$ ( $=1$ if $A$ occurs and $=0$ otherwise). Intuitively, $Y_{1 i}$ regulates when zero costs occurs and $Y_{2 i}$ is the logarithm (base 10) of non-zero costs. Zhang et al. [30] extend the two-part structure in Duan [31] to model the distributions of the two latent random variables $Y_{1 i}$ and $Y_{2 i}$. This model is at the individual level and adjusts for individual level characteristics. Specifically,

$$
\begin{aligned}
& Z_{i}=I\left[Y_{1 i}>0\right] \times 10^{Y 2 i} \\
& \text { Model 1: } Y_{1 i}=\alpha_{0}+\alpha_{1} \mathbf{X}_{1 i}+\varepsilon_{1 i} \quad \varepsilon_{1 i} \sim N(0,1)
\end{aligned}
$$

$$
\text { Model 2: } Y_{2 i}=\beta_{0}+\beta_{1} \mathbf{X}_{2 i}+\varepsilon_{2 i} \quad \varepsilon_{2 i} \sim N\left(0, \sigma_{2}^{2}\right) \text {. }
$$

In these models, the covariates $\boldsymbol{X}_{1 i}$ and $\boldsymbol{X}_{2 i}$ can be different subsets of the complete set of observed characteristics, $\boldsymbol{X}_{i}$ and the variance of $\varepsilon_{1 i}$ is set to one for identifiability. A consequence of Model 2 is that the actual nonzero costs are specified as a log-normally distributed random variable. An important feature of a log-normally distributed random variable model is the distribution is skewed and that the variance is exponentially increasing in the levels of the $\boldsymbol{X}_{2 i}$ [30]. Estimation for the models defined by (1) and (2) is carried out using maximum likelihood estimation.

In the regression models, we use Model 1 to model the zero cost and Model 2 to model the cost level. We use the comorbidity index age, gender, comorbidity, mental illness, pregnancy, and drug/alcohol addiction as explanatory variables. One often defines the log normal distribution in terms of the natural logarithm, rather than base 10 used here, but other logarithmic bases lead to the same family of distributions with rescaled parameters.

\section{Abbreviation}

MMC: Medicaid managed care.

\section{Competing interests}

The authors declare that they have no competing interests.

\section{Authors' contributions}

MC Conceived of study and participated in its design and analysis and drafted the manuscript. MW Participated in its design and analysis and drafted the manuscript. WM and BK Participated in design of study and reviewed and revised the manuscript. VD Participated in design of the study, provided the data and reviewed the manuscript. All authors read and approved the final manuscript.

\section{Authors' information}

VD: Chief Medical Officer at MetroPlus Health Plan.

WM: CEO/CMO, Gotham Health, NYC Health and Hospitals Corporation.

\section{Author details}

${ }^{1}$ Division of Clinical Epidemiology and Evaluative Sciences Research and Center for Integrative Medicine at Weill Cornell Medical College, New York, USA. ${ }^{2}$ Department of Statistical Science, Cornell University, Ithaca, NY, USA. ${ }^{3}$ Gotham Health, NYC Health and Hospitals Corporation, New York, USA. ${ }^{4}$ MetroPlus Health Plan, New York City Health and Hospitals Corporation, New York, USA. ${ }^{5}$ Center for Integrative Medicine, Weill Cornell Medical College, 1300 York Avenue, Box 46, New York, NY 10065, USA.

Received: 14 May 2014 Accepted: 15 September 2014

Published: 14 November 2014

\section{References}

1. Sparer M: Medicaid Managed Care: Costs, Access, and Quality of Care. Princeton, NJ: Robert Wood Johnson Foundation; 2012.

2. Lewin Group Medicaid Managed Care Cost Savings: A Synthesis of 24 Studies Working Paper 17236 (Prepared for America's Health Insurance Plans). Falls Church, VA: The Lewin Group; 2009

3. Duggan M, Hayford $T$ : Has the shift to managed care reduced medicaid expenditures? Evidence from state and local level mandates. J Policy Anal Manage 2013, 32(3):505-535.

4. Centers for Medicare \& Medicaid Services, Office of the Actuary, National Health Statistics Group: Center for Medicare and Medicaid Services National Health Expenditures Projects 2009-2010 October. 2010.

5. Charlson M, Charlson RE, Briggs W, Hollenberg J: Can disease management target patients most likely to generate high costs? The impact of comorbidity. J Gen Intern Med 2007, 22(4):464-469.

6. Charlson M, Charlson R, Peterson J, Marinopoulos S, Briggs W, Hollenberg J: The Charlson comorbidity index is adapted to predict costs of chronic disease in primary care patients. J Clin Epidemiol 2008, 61(12):1234-40.

7. Deyo R, Cherkin D, Ciol M: Adapting a clinical comorbidity index for use with ICD-9-CM administrative databases. J Clin Epidemio/ 1992, 45(6):613-9

8. Shern DL, Jones K, Chen HJ, Jordan N, Ramoni-Perazzi J, Boothroyd RA: Medicaid managed care and the distribution of societal costs for persons with severe mental illness. Am J Psychiatry 2008, 165(2):254-60.

9. Charlson M, Pompei P, Ales K, MacKenzie R: A new method of classifying prognostic comorbidity in longitudinal studies: development and validation. J Chronic Dis 1987, 40(5):373-83.

10. Koenker R, Machado AF: Goodness of fit and related inference processes for quantile regression. J Am Stat Assoc 1999, 94:1296-1310.

11. Koenker R, Hallock KF: Quantile regression. J Econ Perspect 2001, 15:143-156.

12. Boyd CM, Boult C, Shadmi E, Leff B, Brager R, Dunbar L, Wolff JL, Wegener S: Guided care for multimorbid older adults. Gerontologist 2007, 47(5):697-704 
13. Noel P, Parchman ML, Williams JW Jr, Cornell JE, Shuko L, Zeber JE, Kazis LE, Lee AF, Pugh JA: The challenges of multimorbidity from the patient perspective. J Gen Intern Med 2007, 22(Suppl 3):419-424.

14. Valderas JM, Starfield B, Sibbald B, Salisbury C, Roland M: Defining comorbidity: implications for understanding health and health services. Ann Fam Med 2009, 7(4):357-63.

15. Verdier J, Byrd V, Stone C: Enhanced Primary Care Case Management Programs in Medicaid: Issues and Options for States Center for Health Care Strategies, Inc Prepared for Center for Health Care Strategies and Oklahoma Health Care Authority. 2009.

16. Arora R: Designing and Implementing Medicaid Disease and Care Management Programs: A User's Guide. Falls Church, VA: The Lewin Group. March 2008(AHRQ Publication No. 07(08)-0063).

17. Rosenman MB, Holmes AM, Ackermann RT, Murray MD, Doebbeling CC, Katz B, Li J, Zillich A, Prescott VM, Downs SM, Inui TS: Indiana Chronic Disease Management program risk stratification analysis. Med Care 2005, 43(10):979-84

18. Short P, Graefe D, Schoen C, Churn, Churn, Churn: How Instability of Health Insurance Shapes American's Uninsured Problem. In Task Force on the Future of Health Insurance. New York: Commonwealth Fund; 2003.

19. Hoffman C, Rice D, Sung H: Persons with chronic conditions. Their prevalence and costs. JAMA 1996, 276(18):1473-9.

20. Ellrodt G: Evidence-based disease management. JAMA 1997, 27(20):1687-1692.

21. Yu W, Ravelo A, Wagner TH, Phibbs CS, Bhandari A, Chen S, Barnett PG: Prevalence and costs of chronic conditions in the VA health care system. Med Care Res Rev 2003, 60(3 Suppl):146S-167S.

22. Forrest C, Lemke KW, Bodycombe DP, Weiner JP: Medication, diagnostic, and cost information as predictors of high-risk patients in need of care management. Am J Manag Care 2009, 15(1):41-8.

23. Gifford K: Medicaid and the uninsured: A profile of Medicaid Managed Care Programs in 2010: Findings from a 50 State Survey, Henry J Kaiser Foundation. 2011 (\#8220).

24. Iglehart J: Desperately seeking savings: states shift more Medicaid Enrollees to Managed Care. Health Aff 2011, 30:1627-1629.

25. Kronick R, Gilmer T, Dreyfus T, Lee L: Improving health-based payment for Medicaid beneficiaries: CDPS. Health Care Financ Rev 2000, 21(3):29-64.

26. Kuhlthau K, Ferris TG, Davis RB, Perrin JM, lezzoni LI: Pharmacy-and diagnosis-based risk adjustment for children with Medicaid. Med Care 2005, 43(11):1155-9.

27. Winkelman R, Damler R: Risk adjustment in State Medicaid Programs. Health Watch 2008, 57:1-34.

28. The Evolution of Managed Care in Medicaid: Report to the Congress MACPAC: Medicaid and CHIP Payment and Access Commission. Washington DC: MACPAC; 2011.

29. Charlson ME, Charlson RE, Peterson JC, Marinopoulos SS, Briggs WM, Hollenberg JP: The Charlson comorbidity index can be used prospectively to identify patients who will incur high future costs. J Clin Epidemiol 2008, 61(12):1234-1240.

30. Zhang M, Strawderman RL, Cowen ME, Wells MT: Bayesian Inference for a Two-Part Hierarchical Model: An Application to Profiling Providers in Managed Health Care. J Am Stat Assoc 2006, 101:934-945.

31. Duan N, Manning WG Jr, Morris CN, Newhouse JP: Choosing between the sample selection model and the multi-part model. J Bus Econ Stat 1984, 2:283-289.

\section{Submit your next manuscript to BioMed Central and take full advantage of:}

- Convenient online submission

- Thorough peer review

- No space constraints or color figure charges

- Immediate publication on acceptance

- Inclusion in PubMed, CAS, Scopus and Google Scholar

- Research which is freely available for redistribution 